\title{
A CASE REPORT ON: EXTRAGENITAL AND GENITAL LSA
}

Suraj Bali ${ }^{1}$, Mrityunjay Kumar Singh ${ }^{2}$, Mayank Singh ${ }^{3}$, Himanshu Rana ${ }^{4}$

\section{HOW TO CITE THIS ARTICLE:}

Suraj Bali, Mrityunjay Kumar Singh, Mayank Singh, Himanshu Rana. "A Case Report on: Extragenital and Genital LSA". Journal of Evolution of Medical and Dental Sciences 2015; Vol. 4, Issue 61, July 30; Page: 10720-10723,

DOI: $10.14260 /$ jemds/2015/1545

ABSTRACT: Lichen sclerosus et atrophicus (LSA) is a disease of unknown etiology. Although the anal and genital regions are predominantly affected, $2.5 \%$ of patients only present with extra genital lesions-particularly of the trunk, neck, and upper limbs. The wrists, palm plantar regions, nipples, and face are less commonly involved. We report here a case of rare presentation of extra genital LSA associated with genital LSA.

KEYWORDS: LSA (Lichen sclerosus et atrophicus), Extragenital LSA, Genital LSA, PUVASOL.

INTRODUCTION: Lichen sclerosus et atrophicus (LSA), is a chronic skin disease that is common in women. It is most frequently located over the anogenital region, but it can also affect any part of the skin or mucosal surface.[1] The generalized form is very rare. Although the etiopathogenesis is unclear, primary suspects include autoimmune factors. ${ }^{[2]}$ Primary lesions are usually papules that are uniform in shape, ivory colored, with defined borders and a depression in the middle.[1] In our case report extra genital LSA is associated with anogenital LSA, in which extra genital LSA involved almost all part of body.

CASE REPORT: A 28-years-old man presented with skin lesions on both forearm, both dorsum of hands, involving finger web spaces, on both legs and dorsum of feet for two years. Later these lesions also involved tip of penis, groins, and axilla. Few lesions were also present on abdomen, prepuce and glans, and some on anterior part of scalp. Initially these lesions started as small itchy papule on forearm and dorsum of hands. Later they gradually coalesce in size forming a sclerotic plaque type lesion, ivory white in color with shiny or wrinkled surface with mild itching present occasionally over extra genital lesion. Pain and itching was present over genital lesion. H/o repeated sunburn of skin present, there is no h/o repeated trauma, dysuria, pain on defecation, but pain occur when pt. retract the foreskin of penis. There were no complaints suggestive of any systemic Involvement and also there is no significant family history.

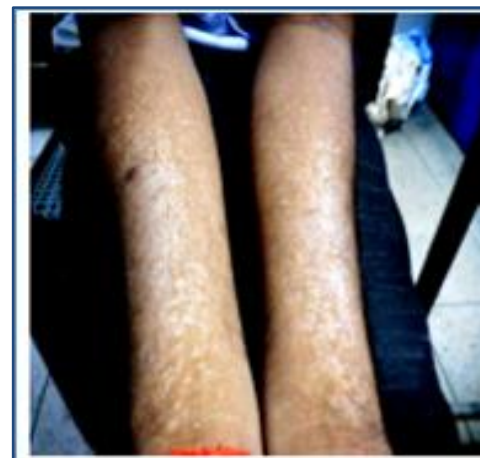

Figure 1

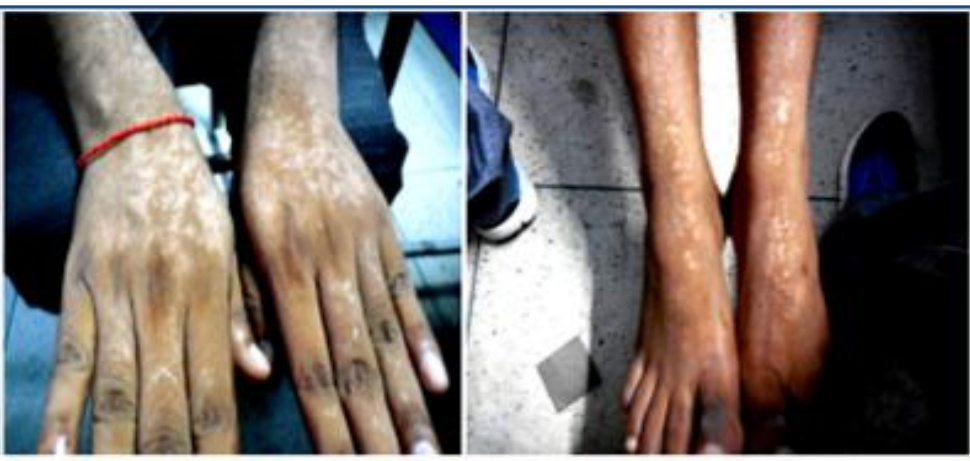

Figure 2
Figure 3 


\section{CASE REPORT}
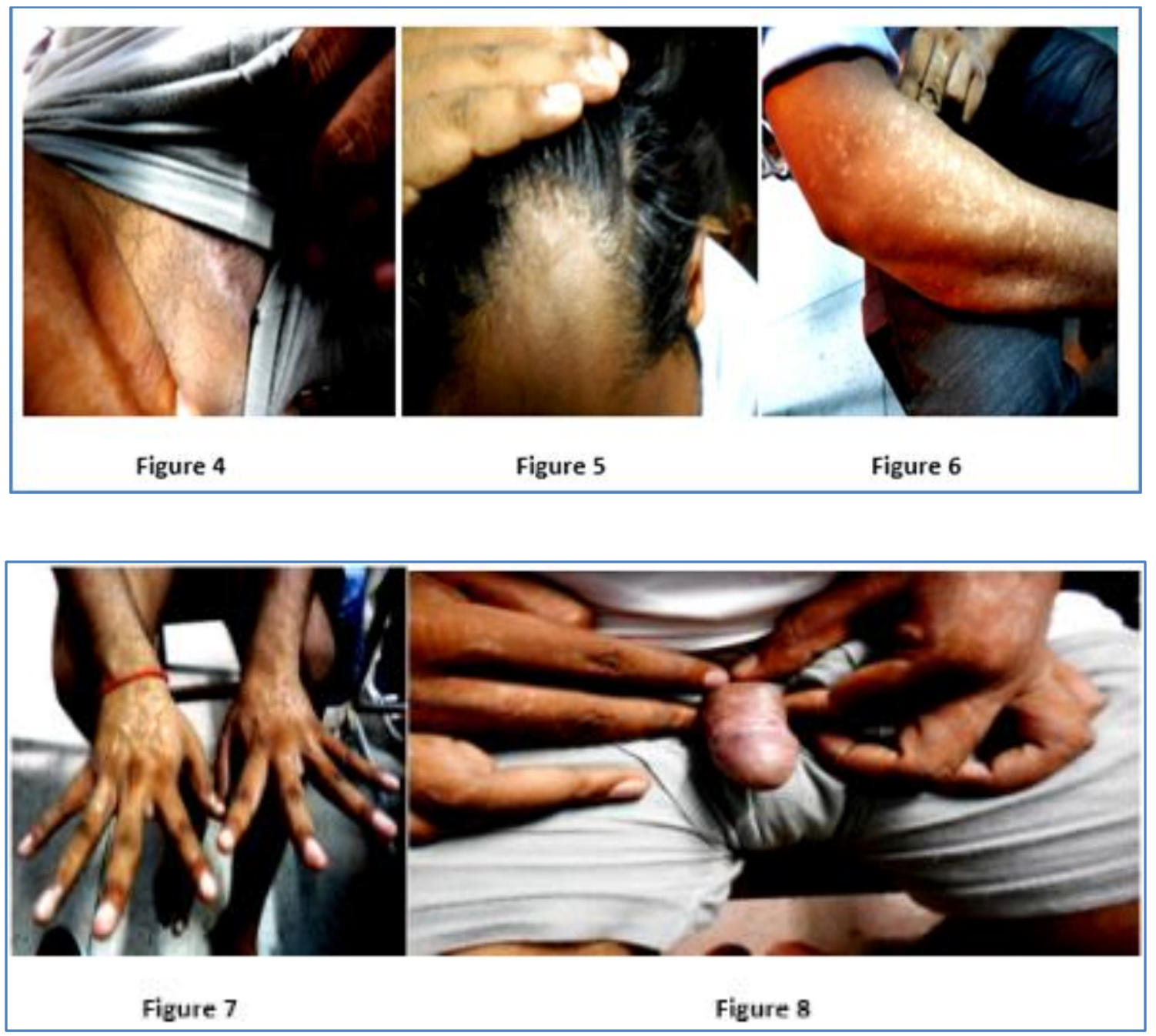

Figure 1 to 8: (Photographs of patient) showing Extragenital and genital LSA lesions, before Treatment

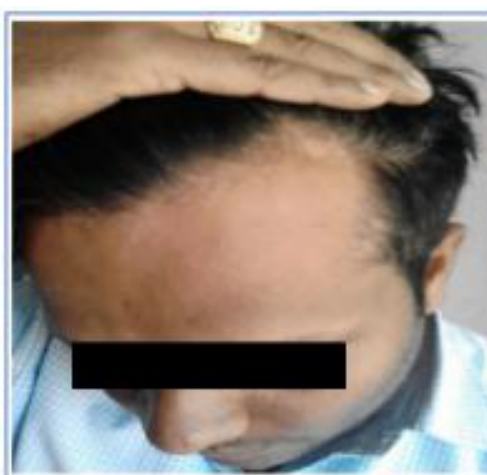

Figure 9

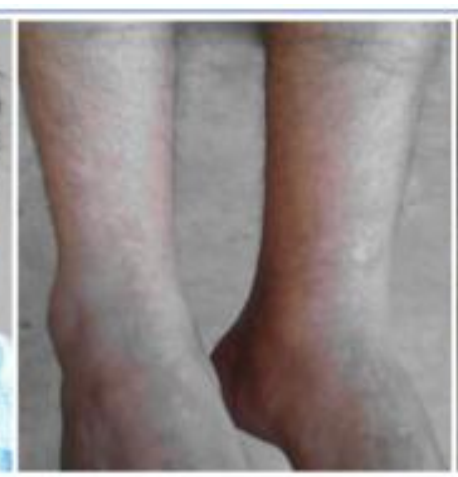

Figure 10



Figure 11 


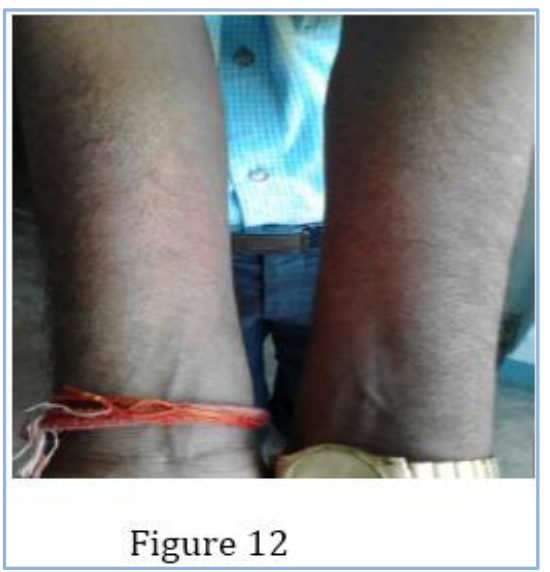

\section{Figure 9 to 12: (Photographs of Patient)} showing response after treatment

Examination revealed multiple ivory white colored plaque type of lesions, variable in size present over forearm, arm, dorsum of hands, finger web spaces, on anterior part of scalp, in axilla, over legs and dorsum of feet, groins and at the tip of penis. The sclerotic plaques are covered with a fine wrinkled (often referred to as cigarette paper-or parchment -like) epidermis. Routine blood investigations were within normal limits. A skin biopsy was taken with a clinical differential diagnosis of Post inflammatory hypopigmentation, vitiligo, pityriasis versicolor and morphea.

HISTOPATHOLOGY: Microscopic-serial sections studied sections show orthokeratotic stratum corneum covered epidermis with focal thinning and vacolar alteration of the basal layer. Underlying superficial epidermis shows focal band like lymphohistiocytic inflammatory infiltrate. Mild perivascular lymphocytic infiltrate also seen.

DIAGNOSIS: Lichen Sclerosus et atrophicus. (LSA).

DISCUSSION: LSA is a rare, chronic inflammatory dermatitis that affects both the dermis and epidermis. Although the etiopathogenesis is not exactly known, Borrelia infections, hepatitis C infections, genetic factors, and androgen level irregularities are thought to be related.[1] LSA is more frequently seen in females, and it can occur at any age. The prevalence peaks in the fifth and sixth decades of life, and between the ages of 8 and 13. ${ }^{[3]}$ Although it is commonly seen in the anogenital area (83-98\%), it can be seen in extra genital areas in $15-20 \%$ of patients.[4,5]

Extragenital LSA is most commonly located on the neck, upper arms, and flexor surfaces of the wrist; [6] however, generalized LSA has not been commonly reported in the literature.[3]In our case patient has predominantly extra genital lesion covering most of body surface area also with genital lesions.

Extragenital LSA without accompanying genital lesions was recorded in 805 of 4280 cases reviewed by Meffert et al.[6] LSA is most common on the neck, shoulders, and upper portion of the trunk. It is generally asymptomatic, but occasionally pruritic. Most lesions of extra genital LSA present as flat, white, polygonal papules, and slight atrophic white plaques.[7]

Phototherapy (UVA1, PUVA), surgery and topical tacrolimus are available for treatment. Generalized LS treatments include phototherapy (PUVA, UVA1), hydroxychloroquine, pulsated systemic corticosteroids, and methotrexate combinations.[3,8] Our Patient kept over PUVASOL and 
topical Tacrolimus $0.1 \%$ and emollient from last 8 months and shown good response. Which could be seen in photographs (Figure 9 to 12)?

CONCLUSION: This is a case of rare presentation of generalized extra genital LSA and it's association with genital LSA. Diagnosis was made by mainly by clinically and supported by histopathologic findings. Patient has shown good response after treatment with PUVASOL and topical tacrolimus $0.1 \%$.

\section{REFERENCES:}

1. Tasker GL, Wojnarowska F. Lichen sclerosus. Clin Exp Dermatol 2003; 28:128-33.

2. Oyama N, Chan I, Neill SM, South AP, Wojnarowska F, Kawakami Y, et al. Development of antigen -specific ELISA for circulating autoantibodies to extracellular matrix protein 1 in lichen sclerosus. J Clin Invest 2004; 113:1550-9.

3. Smith YR, Haefner HK. Vulvar lichen sclerosus: Pathophysiology and treatment. Am J Clin Dermatol 2004; 5:105-25.

4. Heymann WR. Lichen sclerosus. J Am Acad Dermatol 2007; 56:683-4.

5. Coelho WS, Diniz LM, Souza Filho JB. Lichen sclerosus et atrophicus - Report of two cases with atypical presentations. an Bras Dermatol 2006; 81:297-300.

6. Choi SW, Yang JE, Park HJ, Kim CW. A case of extragenital lichen sclerosus following Blaschko's lines. J Am Acad Dermatol 2000; 43:903-4.

7. Pavlovic MD. Linear lichen sclerosus with underlying bony atrophy. J Am Acad Dermatolo 2004;50(3):E4

8. Neill SM, Lewis FM, Tatnall FM, Cox NH, British Association of Dermatologists. British Association of Dermatologists' guidelines for the management of lichen sclerosus 2010. Br J Dermatol 2010; 163:672-82.

\section{AUTHORS:}

1. Suraj Bali

2. Mrityunjay Kumar Singh

3. Mayank Singh

4. Himanshu Rana

\section{PARTICULARS OF CONTRIBUTORS:}

1. Assistant Professor, Department of Skin and V. D, LLRM Medical College, Meerut, Uttar Pradesh.

2. Assistant Professor, Department of Skin and V. D, Pt. JNM Medical College, Raipur, Chhattisgarh.

3. Post Graduate Student, Department of Skin and V.D, LLRM Medical College, Meerut, Uttar Pradesh.

FINANCIAL OR OTHER COMPETING INTERESTS: None
4. Post Graduate Student, Department of Skin and V.D, LLRM Medical College, Meerut, Uttar Pradesh.

\section{NAME ADDRESS EMAIL ID OF THE CORRESPONDING AUTHOR:}

Dr. Mrityunjay Kumar Singh,

Flat No. F-9, Block -2,

Medical College Campus, Mekahava,

Raipur-492001, Chhattisgarh.

E-mail: mrityunjay25.ms@gmail.com

Date of Submission: 08/07/2015.

Date of Peer Review: 09/07/2015.

Date of Acceptance: 22/07/2015.

Date of Publishing: 30/07/2015. 